\title{
TITLE:
}

\section{$<$ Note> Ecological Aspects of Chimpanzee Insectivory in the Budongo Forest, Uganda}

\section{$\operatorname{AUTHOR}(\mathrm{S})$ :}

Hedges, Sophie; McGrew, William C.

\section{CITATION:}

Hedges, Sophie ... [et al]. < Note> Ecological Aspects of Chimpanzee

Insectivory in the Budongo Forest, Uganda. Pan Africa News 2012, 19(1):

6-7

ISSUE DATE:

2012-06

URL:

http://hdl.handle.net/2433/157937

RIGHT:

Copyright (C) Pan Africa News. 


\section{<NOTE> \\ Ecological Aspects of Chimpanzee Insectivory in the Budongo Forest, Uganda}

\section{Sophie Hedges \& William C. McGrew}

Department of Archaeology \& Anthropology, University of Cambridge, UK

(E-mail:wcm21@cam.ac.uk)

\section{INTRODUCTION}

All long-term studies of chimpanzees (Pan troglodytes) show that they habitually eat insects, most often social insects obtained by extractive foraging with simple tools ${ }^{1}$. This generalisation holds across Africa from Senegal to Tanzania, but Ugandan populations are exceptional: Except for Kalinzu with ant dipping for Dorylus ${ }^{2}$, no other Ugandan long-term study site (Budongo, Kanyawara, Ngogo, Semliki) shows regular insectivory, technically-aided or otherwise ${ }^{3}$. At Budongo, only occasional cases of eating Cubitermes have been recorded ${ }^{4}$. This dearth is puzzling, especially when these sites are compared with those (Gombe, Mahale) of neighbouring Tanzania, which have well-documented and varied elementary technology $y^{5,6}$.

Lack of insectivory could reflect basic environmental constraints: Absence or scarcity of prey species, or absence or scarcity of raw materials for tools ${ }^{7}$. Less likely alternative explanations are differences between Ugandan and non-Ugandan populations in terms of genome, diet, manual dexterity, intelligence, or appetite. The presence of ant dipping at Kalinzu casts doubt on all these alternatives. Finally, such inter-population differences could result from differences in cultural knowledge, as has been found elsewhere ${ }^{8}$. That is, some populations of chimpanzees may not have discovered that some insects are edible or can be got with technical assistance.

Our study sought to explore the role of environmental constraints in the absence of regular insectivory in the Budongo Forest Reserve, Uganda.

\section{METHODS}

The study was done in the Sonso region Budongo from 14 July-8 September, 2011. Subjects were 80+ wellhabituated chimpanzees (Pan troglodytes schweinfurthii) of the Sonso community ${ }^{9}$. SH did 12 line-transects of 6 $\mathrm{m}$ width, each of $500 \mathrm{~m}$ length, along the existing grid system of trails; six ran north-south and six ran east-west. Sites of transects were balanced for the two main forest types, mixed (4,260 m) and swamp (1,740 m). Distances were measured by hip-chain, while another person scanned for evidence of social insects. Total area surveyed was 3.6 ha.

The following taxa (all known to be eaten by chimpanzees elsewhere in East Africa) were sought: Cubitermes, Macrotermes, and Pseudacanthotermes termites; Dorylus (army) and Oecophylla (weaver) ants; and Apis (honey) bees. SH checked termite mounds for activity and measured their height and circumference; this allowed calculation of their volume, either as a cylinder or cone. Encounters with Dorylus ants on trails were noted by GPS data on time and place. Mounds and nests of all species were monitored weekly, after initial datacollection and surface clearing of debris. On each visit, $\mathrm{SH}$ checked for insect activity and signs of chimpanzee or other predator presence or exploitation. Specimens of prey species were preserved and identified later by specialists.

$\mathrm{SH}$ surveyed raw materials suitable for extractive foraging probes, that is, woody and non-woody vegetation with straight, elongate dimensions. Data-collection entailed marking a circle of $5 \mathrm{~m}$ radius around the resource and counting all plants presenting potential raw materials, in three categories: woody tree or shrub, vine, or monocotyledon (e.g. grass, sedge $)^{10}$.

To measure the chimpanzees' consumption of insects, both direct and indirect data were collected. SH logged 80 hr of direct observation of opportunistically encountered parties of chimpanzees, using continuous recording of feeding or interacting with insects ${ }^{11}$. For indirect data, SH collected all fresh faecal samples $(n=26)$ from chimpanzees encountered; these were sealed in ziplock bags and later sluiced in running water to detect undigested food fragments ${ }^{12}$.

To estimate productivity, that is, amount of termites available to harvest, $\mathrm{SH}$ randomly sampled 10 Cubitermes and two Pseudacanthotermes mounds, removing about $150 \mathrm{~cm}^{3}$ from their tops. Once sealed in a ziplock bag, the soil was broken into chunks of less than $1 \mathrm{~cm}^{3}$; all termites, by caste, were counted in the contents ${ }^{7}$. Also, $\mathrm{SH}$ made and used flexible probes modelled on chimpanzee fishing probes, to fish termites from these mounds. To measure the payoff from termite fishing, efficiency, success rate, and error rate were calculated ${ }^{12}$.

Because sample sizes were small and data non-normally distributed, all statistical tests were non-parametric. Alpha was set at 0.05 , and all tests were two-tailed.

For specific details of methods, see Hedges ${ }^{13}$.

\section{RESULTS}

Cubitermes ugandensis mounds were found at a mean density of 34.4 mounds/ha (SEM = 8.17). Neither Macrotermes bellicosus nor Pseudacanthotermes spiniger mounds were found on transects, but two mounds of each genus were found and monitored elsewhere. Two chimpanzees were seen to eat soil from mounds, one of Pseudacanthotermes and one of Cubitermes. Two mounds (one of each genus) showed damage from chimpanzee predation, but the two Macrotermes mounds showed no signs of chimpanzee use.

Volume of termite mounds varied greatly but did not differ across forest types. Mean volume of Macrotermes mounds was almost 300 times that of the average Cubitermes mound, and mean volume of Pseudacanthotermes mounds was almost seven times as big.

Encounter rate over 6 days of Dorylus (wilverthi or kohli) columns on trails was 0.20 columns per $\mathrm{km}$ and 0.42 columns per hr. Neither Apis mellifera nor Dorylus nests were found on transects, but one of each was found and monitored elsewhere. 
Raw materials for fishing probes were superabundant. Cubitermes mounds afforded a mean of 580 tool sources per mound, while the numbers of sources for other insect prey species were: Macrotermes (155), Pseudacanthotermes (460), Dorylus (440), and Apis (684). Availability of raw materials did not differ across prey species, but overall, woody plants predominated over monocots or vines in abundance.

None of the 26 faecal specimens yielded insect remains.

The 12 mounds assessed for termite availability yielded an average of 104.8 termites per sample, but the range of values was huge (0-361).

SH's fishing from Cubitermes mounds was minimally productive, as the passageways were narrow and the soldiers passive. Fishing was a far less useful harvesting technique than detaching portions of the mound, with mean yields of 2.4 versus 123.5 termites. Pseudacanthotermes showed the reverse: Fishing was far more productive than detaching soil, with mean yields of 139 versus 11.5 termites. Fishing the two Macrotermes mound yielded almost nothing (mean of 2.5 termites).

\section{DISCUSSION}

Availability of prey or of raw materials seems not to be an obstacle to Budongo chimpanzees using tools to obtain insects. The low abundance of mounds of Macrotermes and Pseudacanthotermes is within the range of densities at other sites where these genera are fished: Bilenge (0.35/ha, Macrotermes; 1.03, Pseudacanthotermes); Campo (0.68/--); Gombe $(0.40 / 2.04)$, etc. Similarly, the density of Cubitermes mounds at Budongo, at 34.4 mounds/ha, where the termites are eaten without tools, is intermediate in a wide range of values: 0.8/ha at Gombe at one extreme, to 233.8/ ha at Lui Kotale at the other.

Similarly, encounter rates for Dorylus at Budongo, measured by either distance or time, are comparable to those from other sites. For distance, Budongo's encounter rate of $0.2 / \mathrm{km}$ is close to Gashaka's dry season rate of 0.21 , where the highest rate of consumption of Dorylus by chimpanzees has been recorded. For time, Budongo's rate of $0.42 / \mathrm{hr}$ also resembles Gashaka's at $0.43^{14}$.

Too few data are available to compare abundance of Apis nests between Budongo and other sites. Similarly, too few data have been published or were obtained here to allow confident comparison of termite mound volumes.

Consumption of termite soil (and termites) by chimpanzees varies hugely. Budongo's rate of $0.79 / 100 \mathrm{hr}$ of such geophagy is higher than that at Kibale (0.52) but much lower than that at Kasoje $(4.07)^{15}$. This report of Sonso chimpanzees eating the soil of Pseudacanthotermes appears to be a first for this genus in Uganda.

Raw materials of all types for extractive probes are readily available. To take the most pertinent case, Budongo's Macrotermes mounds afforded 155 raw material sources on average, compared with a range from 37 at Assirik to 228 at Semliki.

Absence of termites in chimpanzee faecal samples replicates the results of an earlier study ${ }^{4}$, confirming that insectivory is rare.
Technical (i.e. fishing) versus non-technical (i.e. detachment) acquisition of termites seems not to have been compared systematically before this study. The closest result to ours seems to be that tools and techniques used to obtain Dorylus differ according to species of ant $^{8}$. But until the chimpanzees of Budongo learn to eat Pseudacanthotermes and Macrotermes, these differences remain hypothetical.

In conclusion, the most likely explanation for the lack of extractive foraging for insects by Budongo chimpanzees is lack of cultural knowledge.

\section{ACKNOWLEDGEMENTS}

We thank: Uganda Wildlife Authority (UWA) and Uganda National Council for Science and Technology (UNCST) for permission to do research; K. Zuberbuehler and G. Muhanguzi for permission to work at BCFS; Corpus Christi College; Department of Biological Anthropology; and the Mosley, Frere, and Worts Funds of University of Cambridge for funding; R. Ogen, G. Muhumuza, C. Hobaiter, and B. Fallon for field assistance; C. Schöning and P. Nyeko for insect identifications.

\section{REFERENCES}

1. McGrew WC 1992. Chimpanzee Material Culture: Implications for Human Evolution. Cambridge University Press, Cambridge.

2. Hashimoto C, Furuichi T, Tashiro Y 2000. Ant dipping and meat eating by wild chimpanzees in the Kalinzu Forest, Uganda. Primates 41:103-108.

3. Watts DP 2007. Tool use by chimpanzees at Ngogo, Kibale National Park, Uganda. Int J Primatol 29:83-94.

4. Newton-Fisher NE 1999. The diet of chimpanzees in the Budongo Forest Reserve, Uganda. Afr J Ecol 37:344-354.

5. Goodall J 1986. The Chimpanzees of Gombe: Patterns of Behavior. Harvard University Press, Cambridge, Mass., and London.

6. Nishida T 2012. Chimpanzees of the Lakeshore: Natural History and Culture at Mahale. Cambridge University Press, Cambridge.

7. McGrew WC, Marchant LF , Beuerlein MM, Vrancken D, Fruth B, Hohmann G 2007. Prospects for bonobo insectivory: Lui Kotal, Democratic Republic of Congo. Int $J$ Primatol 28:1237-1252.

8. Schöning C, Humle T, Möbius Y, McGrew WC 2008. The nature of culture: Technological variation in chimpanzee predation on army ants revisited. J Hum Evol 55:48-59.

9. Reynolds V 2005. The Chimpanzees of Budongo Forest: Ecology, Behaviour and Conservation. Oxford University Press, Oxford.

10. Martin P, Bateson P 2007. Measuring Behaviour: An Introductory Guide. 3rd edition. Cambridge University Press, Cambridge.

11. McGrew WC, Marchant LF, Phillips CA 2009. Standardised protocol for primate faecal analysis. Primates 50:363-366.

12. McGrew WC, Marchant LF 1999. Laterality of hand use pays off in foraging success for wild chimpanzees. Primates 40:509-513.

13. Hedges S 2012. Ecological aspects of chimpanzee insectivory in the Budongo Forest, Uganda. Final-year dissertation, University of Cambridge.

14. Fowler A, Sommer V 2007. Subsistence technology of Nigerian chimpanzees. Int J Primatol 28:997-1023.

15. Mahaney WC, Milner MW, Sanmugadas K, Hancock RGV, Aufreiter S, Wrangham R, Pier HW 1997. Analysis of geophagy soils in Kibale Forest, Uganda. Primates 38:159-176. 